\title{
The Effect of Marijuana Legalization on Anticipated Use: A Test of Deterrence Theory
}

\author{
Christine Arazan ${ }^{1, \#}$, Michael Costelloe ${ }^{1, \#, *}$ and Tricia M. Hall ${ }^{2, \#}$ \\ ${ }^{1}$ Northern Arizona University, USA \\ ${ }^{2}$ Grand Canyon University, USA
}

\begin{abstract}
Marijuana is the most frequently used illicit drug in the world (Erickson, Van Der Maas, and Hathaway, 2013:428). Here in the United States, public support for the legalization of marijuana for recreational use is substantial. With public support, both Colorado and Washington passed state initiatives in 2012 to legalize recreational use of marijuana for individuals aged 21 years and older. Even the federal government has recently reversed their initial position to continue to enforce federal drug laws within these states. With what appears to be increasingly liberal attitudes toward marijuana use and even toward legalization, some are concerned about what this may mean for drug use in America. To many, it appears obvious that with changing attitudes and more lenient policies, use of marijuana will increase and in turn exacerbate a host of individual and societal problems that marijuana use is thought to cause. The primary focus of this study examines the first part of these concerns: to what extent will marijuana use increase with these policy changes? Specifically, this research looks at what extent current abstainers of marijuana might use if it were legalized.
\end{abstract}

Keywords: legalization, marijuana, deterrence theory, college marijuana use, Monitoring the Future.

\section{INTRODUCTION}

Attitudes toward marijuana use are clearly changing in the United States. The Gallup Poll first asked Americans about their views on legalizing marijuana in 1969. At that time, 84 percent of Americans believed marijuana should remain illegal while only 12 percent thought it should be legalized (Swift 2013:1). As the decades have passed, support for the legalization of marijuana has steadily climbed. For example, in 1985 the Gallup Poll showed almost a twofold increase in the percentage of Americans supporting legalization with 23 percent of Americans now favoring marijuana legalization while those supporting criminalization decreased to 73 percent (Swift 2013:1). More recently, the Gallup Poll asked the same question again in 2013, following the legalization of recreational use of marijuana in Colorado and Washington. It found that support for legalization again more than doubled to 58 percent of respondents now approving of it while only 39 percent opposed it (Swift 2013:1). This last dramatic shift toward support for legalization has been relatively recent, increasing ten percent in the last year alone (Swift 2013:1). Support for legalization of marijuana is especially evident among 18 to 29 year olds with 67 percent of this age group indicating support for its legalization (Swift 2013:1).

*Address correspondence to this author at the Northern Arizona University, USA; Tel: 1-928-523-7262; Fax: 1-928-523-8011;

E-mail: Michael.Costelloe@nau.edu

${ }^{\#}$ All authors contributed equally to this project and therefore names are listed alphabetically.
While the number of illicit drug users in general has not increased, the number of marijuana users has grown. In 2011, the National Survey on Drug Use and Health found seven percent or 18.1 million individuals in the United States reported using marijuana in the past month (Substance Abuse and Mental Health Services Administration 2012:1). This is an increase from 2007, when 5.8 percent or 14.5 million individuals reported past month use. Not only is current use for individuals aged 12 and older increasing, but there has also been an increase in marijuana use for individuals aged 18 to 25. In 2008, 16.6 percent of individual's ages 18 to 25 reported using marijuana, while by 2011 this rate of use had increased to 19.0 percent (Substance Abuse and Mental Health Services Administration 2012:2).

Among college students, the target population of the current study, we find similar trends in use. From 1993 to 2001, marijuana use among college students increased from 23 percent to 30 percent (Dierker et al. 2008:681). Since 2001, use has continued to increase, though, at a much more modest pace. In 2010, the Core Alcohol and Drug Survey (CORE) reported that 31.3 percent of college students admitted using marijuana in the past year and 18.1 percent of students reported using marijuana in the past 30 days (SIUC/Core Institute 2012:1).

In response to these increasingly more liberal attitudes toward the use of marijuana, the U.S. has seen, at least in some quarters, corresponding changes in public policy. These transformations have 
taken various forms such as the decriminalization of marijuana possession and the legalization of medical marijuana. However, in 2012, we experienced maybe the most radical departure from marijuana drug policy to date when both Colorado and Washington passed state initiatives to legalize recreational use of marijuana for individuals aged 21 years and older.

Moreover, while initially the federal government vowed to continue to enforce federal drug laws within these states, they have recently reversed that position, signaling a potential shift at the federal level as well. In fact on August 29, 2013, Deputy Attorney General James M. Cole sent out a memorandum to all United States Attorneys regarding the federal government's stance on marijuana enforcement. In this memo, Cole laid out eight objectives the Department of Justice believes should be pursued at the state level. Among these objectives are preventing distribution of marijuana to minors, preventing the diversion of marijuana from states where it is legal to other states where it is not, and preventing drugged driving and the exacerbation of other adverse public health consequences associated with marijuana use (Cole 2013:1-2). At the core of such a stance is the Department of Justice...

expectation that states and local governments that have enacted laws authorizing marijuana-related conduct will implement strong and effective regulatory and enforcement systems that will address the threat those state laws could pose to public safety, public health, and other law enforcement interests.

Of course, along with these changes to marijuana laws also come arguments from opponents of legalization about the negative impact of such laws. A commonly expressed concern about such policies is what affect they may have on the prevalence and incidence of marijuana use. Democratic U.S. Representative Patrick Kennedy is one who opposes the legalization of marijuana. Kennedy, who suffered from alcohol and drug addiction, is worried that the legalization of marijuana sends the wrong message about marijuana (Johnson 2013:1). Before Colorado voted to legalize marijuana, Colorado Governor John Hickenlooper also spoke out in opposition of Colorado's Amendment 64, stating "Colorado is known for many great things-marijuana should not be one of them," he also added "Amendment 64 has the potential to increase the number of children using drugs and would detract from efforts to make Colorado the healthiest state in the nation. It sends the wrong message to kids that drugs are OK" (Ferner 2012:1). Additionally, former democratic President Jimmy Carter said:

I do not favor legalization...we must do everything we can to discourage marijuana use, as we do now with tobacco and excessive drinking...we have to prevent making marijuana smoking from becoming attractive to young people, which is, I'm sure, what the producers of marijuana...are going to try and do (Wing 2013:1).

Implicit in these concerns is the commonly accepted premise that the legalization of marijuana laws will increase use as the fear of punishment is removed. The axiomatic assumption of such arguments is that strict laws against possession and use of marijuana are effective deterrents. However, previous research on deterrence suggests that this may not be the case. In fact, the relatively high prevalence rates for marijuana use on college campuses nationwide suggests that current laws do not deter many college students. If this is true, it may also be true that legalization will not significantly increase use among college students as there may be many reasons for why people choose not to use other than simply fear of formal criminal sanctions. Thus, the primary purpose of this study is to examine the potential effect of legalization on the prevalence of marijuana use among current nonusers on a university campus.

\section{THEORETICAL FRAMEWORK}

Attempts to explain drug use have invoked a number of different theories, including but not limited to social learning theories, social interactionism, and subcultural theories. However, our research questions seem best viewed through the lens of deterrence theory. Specifically, this research examines the extent non-users do not use due to fear of arrest and what potentially may happen to anticipated use when criminal sanctions are removed, which has been a primary issue in the policy debate surrounding marijuana legalization. Consistent with arguments from the opponents of legalization, deterrence theory would suggest that legalization will lead to increases in the prevalence and incidence of marijuana consumption as the legal consequences of consuming marijuana are removed (MacCoun 1993:499). 
Deterrence theory argues that individuals are rational and employ a cost-benefit analysis when making choices and will choose the option where the benefits are perceived to outweigh the potential costs or harm. Applied to criminal acts, it is assumed such costs as the severity, certainty and swiftness of punishment will thus deter individuals from breaking the law when they are deemed greater than the possible benefits of the crime.

When applying deterrence theory, it is important to identify three assumptions. First, deterrence theory assumes that a potential offender knows his or her chances of being arrested, convicted, and punished. However, this of course may not necessarily be true. According to Andenaes (1966:963), "it is often said that criminals tend to be overly optimistic-they are confident that all will work out well. It is possible that the reverse occurs among many law-abiding people; they are deterred because of an over-estimation of the risks" (Andenaes, 1966:963). The second assumption is that for most individuals the costs of committing the criminal act are undesirable and are to be avoided. Finally, the last assumption is that the potential offender acts rationally, more specifically that he or she acts according to the standards of middle-class values (Walker 1994:102). When evaluating this assumption, it is believed by some that individuals are not deterred from committing a criminal act by the fear of punishment, but because they have been socialized into law-abiding behavior (Walker 1994:102). For the purpose of this paper, this means that individuals are taught to abstain from using marijuana because of its illegal status and citizens are raised to value the law and abide by it. If the illegal status and threat of punishment were removed, individuals could then use marijuana and still be adhering to the values that they were taught.

General deterrence occurs when the laws are created to deter all societal members from initially committing criminal acts. Specific deterrence, on the other hand, aims to prevent a specific individual from reoffending. The criminalization of marijuana aims at both general and specific deterrence. Proponents of general deterrence believe that one's knowledge of legal sanctions and the application of those sanctions to others will deter that individual from committing similar criminal acts (Waldo and Chiricos 1972: 533). However, Waldo and Chiricos' study (1972) found, in fact, that the opposite was true. In their study, current marijuana users were twice as likely to know of someone who had been arrested for marijuana possession, suggesting that general deterrence is ineffective in curbing marijuana use. Additionally, Single (1989) reports that there is little empirical support for the claim that marijuana laws exert a strong deterrent effect. In fact, in his study he found no evidence of an increase in marijuana use associated with the decriminalization of marijuana that occurred in the 1970s. It is notable, however, that even with decriminalization there are still penalties in the form of fines that can be imposed and which may produce a deterrent effect.

However, as Andenaes (1996:955) rightly notes just because deterrence appears to not have worked for the perpetrators of crimes, one cannot assume that these laws are not deterring law abiding individuals from using marijuana (Andenaes 1996:955). In other words, because most studies focus on why people use rather than why non-users choose not to, it is difficult to determine the effectiveness of deterrence. Thus, while individuals who use marijuana may not be deterred by current legal sanctions, it may be the very reason nonusers do not smoke marijuana. This paper explores this possibility.

\section{PRIOR LITERATURE}

Variation in the prevalence rates of marijuana use over time exists for several reasons including fluctuations in public approval of use and the perception of risks that come with its use. As the perceptions change, so does marijuana use (Keyes et al. 2011:1791). For example, Monitoring the Future (MTF), a nationwide survey for high school students found that both disapproval of marijuana use and perception of risks have significantly affected marijuana use over the past five decades (Bachman, Johnston, and O'Malley 1998:890). More recently, Beaudoin and Hong (2012) reported a decrease in individual's marijuana use in the last year as well as a decrease in intention to ever use marijuana as perceived risks associated with marijuana use increased (Beaudoin and Hong, 2012:140)

Keyes, et al. (2011) argued that adolescents who matured during times when marijuana was more widely approved of were at higher risk of using marijuana during their teenage years, regardless of individuallevel attitudes toward use, perceived social norms such as attitudes of disapproval by others, and perceived availability (Keyes et al. 2011:1795). These perceptions regarding marijuana use would seemingly affect how one's peers may influence the use or nonuse of marijuana. 
In fact, peer influence is one of the most welldocumented risk factors for marijuana use among adolescents (Keyes et al. 2011:1791). For example, Abiodun and Afolayan (2007) found that 30 percent of college students reported using marijuana because of pressure to do so from their friends, second only behind those who reported using out of curiosity (55.6 percent) but twice the percent (14.8 percent) of those who used for the pleasure they received from smoking the substance (Abiodun and Afolayan, 2007:1071).

Not only do many individuals initially try marijuana due to peer influence, but peer support also increases the likelihood that such behavior will continue. Conversely, if an individual is currently using marijuana, they may quit if they experience disapproval from their peers (Abiodun and Afolayan 2007:1071). During college, many students are doing what they can to fit in with their peers, which often includes conforming to the social norms of the groups with whom they mostly associate. In other words, a college student may engage in marijuana use because of social pressures that promote group conformity allowing for the internalization of group norms and the decision to engage in behaviors that are consistent with newly accepted social norms (Keyes et al. 2011:1796).

While peer influence is a key factor in predicting use or nonuse, nonusers report several other salient reasons for abstaining from smoking cannabis. Using data from the MTF survey, one study (Terry-McElrath, O'Malley, and Johnston 2008) examined the reasons individuals stated for not using marijuana. This study found that between 1977 and 2005 the three most commonly stated reason for either stopping use or never using were (1) concerns about possible psychological damage (63.8 percent), (2) concern about possible physical damage (63.0 percent), and (3) simply not feeling like getting high (61.8 percent) as the top three reasons individuals stopped or never used marijuana.

In regards to deterrence, the same study showed that 45 percent of respondents reported not using because of concern about being arrested (TerryMcElrath et al. 2008: 798). Moreover, individuals who reported having never used marijuana, said more frequently than quitters and continuing users that the primary reason for not using was fear of being arrested (Terry-McElrath et al. 2008: 798). When asking nonusers on a college campus if they would use under the hypothetical condition of future legality, Kohn and Mercer (1971:127) reported that approximately 20 percent of nonusers would be willing to use with this change in policy. In addition, MTF found that in 2012 approximately 56 percent of $12^{\text {th }}$ graders reported they would not use marijuana, even if it were legal and available (Johnston et al. 2013:400)

Many researchers have conducted studies looking at deterrence theory with one of the earliest studies conducted in 1968 by Jack P. Gibbs. In this study, Gibbs found support for deterrence theory by examining the relationship between the certainty and severity of punishment and homicide. Specifically his results supported the idea that the certainty and severity of imprisonment resulted in fewer homicides in all 50 states during the year 1960 (Gibbs 1968:525). Of the two, Gibbs did find that the certainty of punishment had a much greater impact than the severity of punishment, though, he cautioned against rejecting severity as affecting deterrence in some way. The following year, Charles Tittle tested the certainty and severity of punishment in relation to seven index offenses as described in the FBI Uniform Crime Research. Tittle tested certainty of punishment by examining the number of individuals admitted to state prisons for the years 1959-1963. Severity of punishment was operationalized as the mean length of time served by felony prisoners released from state prisons in 1960 (Tittle 1969: 412-413). Consistent with Gibbs study, Tittle found that the certainty of imprisonment had a deterrent effect on criminal behavior. When looking at severity of punishment, Tittle reported a positive relationship between the severity of punishment and crime rates. However, when controlling for levels of urbanization, severity of punishment becomes "irrelevant to the control of deviance" (Tittle 1969:416), supporting the proposition that a punishment that is unlikely to be meted out, no matter how severe, is no deterrent at all.

In 1970, Chiricos and Waldo disputed the findings reported by Tittle in regards to the effect of the certainty of punishment. In their study, certainty was operationalized as imprisonment as a final disposition for crimes known to the police rather than simply looking at total prison admissions (Chiricos and Waldo 1970:203). Chiricos and Waldo (1970) reported that after examining data from 1950,1960, and 1963, there was little reliability of a relationship between certainty of punishment and crime rates. Additionally, they found no clear relationship between severity of punishment and crime rates, which led the authors to conclude that there was "no consistent support for the deterrence hypothesis" (Chiricos and Waldo 1970:207). 
When specifically evaluating research on how deterrence influences marijuana use, Waldo and Chiricos' (1972) study is influential. Waldo and Chiricos (1972) reported that harsh statutory penalties have a minimal deterrent effect if the offender does not believe the court will invoke those penalties, but when an individual believes he/she will be apprehended he/she is less likely to commit the criminal act. For example, they found that individuals who were more likely to report using marijuana perceived that there was only a 0 to 20 percent chance of being apprehended, while those who believed that law violators had more than a 50 percent chance of being apprehended by the police used marijuana at a lower rate if the individual used it at all (Waldo and Chiricos 1972: 532). In addition to this, all of the individuals who perceived arrest for possession as likely (more than 50 percent chance) reported never using marijuana, supporting a potential deterrent effect among nonusers (Waldo and Chiricos 1972: 535).

Burkett and Jensen (1975) also found results that support a deterrent effect among nonusers as a majority of respondents who feared getting caught did not use marijuana while 72 percent of males and 66 percent of females who reported they would probably not get caught reported having at least tried marijuana. These studies support the idea that individuals who do not use marijuana may be deterred from doing so by the punishments one could face if caught. However, it seems also evident that deterrence theory is not supported among those who currently self-report cannabis use.

\section{METHODS}

The primary research question of this study is whether (and to what extent) the removal of criminal justice sanctions may lead to marijuana use among current non-users. In order to answer this primary research question, this study first examines the following secondary research questions:

a. What is the current extent of marijuana use on campus among undergraduates?

b. What is the most commonly identified reason(s) for smoking/not smoking marijuana?

c. Under what specific context are current abstainers most likely to use in the future?

The survey questions for this study came from the Monitoring the Future (MTF) survey and were slightly modified for the purpose of this study. The MTF is a nation-wide survey that measures the extent of drug, alcohol, and cigarette use among young adults in the "past month," "past year," and "lifetime." It also explores trends and changes in the beliefs, attitudes, and behavior about alcohol and drug use (Wadley 2012:1).

Data came from an online self-report survey that was administered to a simple random sample of 4,000 , degree-seeking, undergraduate students in the fall of $2013(\mathrm{~N}=16,817)$. The survey yielded 777 responses with 658 completed surveys resulting in a 17 percent completion rate. This resulted in a confidence interval of plus / minus 5 percent at a 99 percent confidence level. The demographic characteristics for the sample closely approximate the population with two notable exceptions; female and white respondents were slightly overrepresented, which is common in survey research.

In order to examine the current extent of marijuana use on campus among undergraduates and to provide context for our primary research goal, a secondary research question of this study asked respondents to report their marijuana use. Consistent with the MTF marijuana use was operationalized by asking respondents "on how many occasions (if any) have you ever used marijuana recreationally." The respondents were asked about their lifetime use, use in the last year, and use in the past thirty days. Consistent with LaBrie, Hummer, and Lac (2011:718), a dichotomous variable was created that classified those respondents who self-reported using marijuana on zero occasions in the past 12 months and those respondents who have never used as "abstainers" $(n=369)$, while respondents who self-reported using marijuana in the last 12 months $(n=258)$ were classified as "users."

To identify the most commonly identified reason(s) for not smoking marijuana, abstainers were provided with the following 17 statements indicating reasons why some people do not use marijuana and were asked to select all that applied to them.

- Concerned about possible psychological damage

- $\quad$ Concerned about possible physical damage

- $\quad$ Concerned about getting arrested

- Concerned about becoming addicted to marijuana

- It's against my beliefs 
- $\quad$ Concerned about loss of energy and ambition

- Concerned about possible loss of control of myself

- It might lead to stronger drugs

- $\quad$ Not enjoyable, I didn't like it

- $\quad$ My parents would disapprove

- My husband/wife (or boyfriend/girlfriend) would disapprove

- I don't like being with the people who use it

- My friends don't use it

- I might have a bad trip

- Too expensive

- $\quad$ Not available

- Don't feel like getting high

Conversely, individuals who reported using marijuana at least once in the past year were provided 13 statements indicating why some people use marijuana and were asked to select all that applied to them. The statements included:

- To experiment

- To relax or relieve tension

- To feel good or get high

- $\quad$ To seek deeper insights and understanding

- To have a good time with my friends

- To fit in with a group I like

- $\quad$ To get away from my problems or troubles

- Because of boredom, nothing else to do

- Because of anger or frustration

- To get through the day

- To increase the effects of some other drug(s)

- To decrease (offset) the effects of some other drug(s)

- $\quad$ Because I am "hooked" - I have to have it.
Four context questions were developed to estimate under what situations abstainers might report using marijuana in the future. For each of these four contexts, abstainers were asked to indicate on a scale of one to ten (with one being zero percent likely to use and ten being 100 percent likely to use) how likely it was that they might use under the following contexts:

Context One: if it was legalized in this state

Context Two: if you were visiting Colorado or Washington state where recreational use is legal

Context Three: if you were in Amsterdam, Netherlands where the official drug policy is one of tolerance and marijuana use is decriminalized

Context Four: if it was illegal, but your best friend was smoking it

If and to what degree criminal sanctions are removed or lessened, then, varies across the different contexts. In the first two contexts the possibility of sanctions are completely removed. In the third context, the threat of incarceration is absent and social stigma is minimized, but fines and other penalties still occur. Finally, the last context does not remove the threat of punishment at all but includes peer influence as a possible motive for future use, which has been shown to be a consistent predictor of use (Keyes et al. 2011:1791).

Two measurements were used in order to examine the primary research question of whether (and to what extent) the removal of criminal justice sanctions may lead to marijuana use among current abstainers. The first question is an ordinal measure that asked respondents, "do you think you will be using marijuana recreationally five years from now if it were legal in the state you were residing," with the following attributes:

"I definitely will,"

"I probably will,"

"I probably will not," and

"I definitely will not."

The second question asked, "if marijuana were legal and legally available, which of the following would you be most likely to do:"

"not use, even if legal and available,"

"try it," 
Table 1: Extent of Marijuana Use

\begin{tabular}{|c|c|c|c|c|c|c|c|c|}
\hline \multicolumn{8}{|c|}{ On how many occasions (if any) have you smoked marijuana recreationally ... reported in percentages } \\
\hline & $\mathbf{0}$ & $\mathbf{1 - 2}$ & $\mathbf{3 - 5}$ & $\mathbf{6 - 9}$ & $\mathbf{1 0 - 1 9}$ & $\mathbf{2 0 - 3 9}$ & $\mathbf{4 0 +}$ & Total \\
\hline \hline $\begin{array}{c}\text { In the last 30 } \\
\text { days? }\end{array}$ & $\begin{array}{c}74.1 \\
(\mathrm{n}=466)\end{array}$ & $\begin{array}{c}7.6 \\
(\mathrm{n}=48)\end{array}$ & $\begin{array}{c}2.9 \\
(\mathrm{n}=18)\end{array}$ & $\begin{array}{c}3.7 \\
(\mathrm{n}=23)\end{array}$ & $\begin{array}{c}3.8 \\
(\mathrm{n}=24)\end{array}$ & $\begin{array}{c}2.5 \\
(\mathrm{n}=16)\end{array}$ & $\begin{array}{c}5.4 \\
(\mathrm{n}=34)\end{array}$ & $\begin{array}{c}100.0 \\
(\mathrm{n}=629)\end{array}$ \\
\hline $\begin{array}{c}\text { In the last 12 } \\
\text { months? }\end{array}$ & $\begin{array}{c}59.0 \\
(\mathrm{n}=372)\end{array}$ & $\begin{array}{c}11.1 \\
(\mathrm{n}=70)\end{array}$ & $\begin{array}{c}4.6 \\
(\mathrm{n}=29)\end{array}$ & $\begin{array}{c}4.1 \\
(\mathrm{n}=26)\end{array}$ & $\begin{array}{c}4.6 \\
(\mathrm{n}=29)\end{array}$ & $\begin{array}{c}3.5 \\
(\mathrm{n}=22)\end{array}$ & $\begin{array}{c}13.2 \\
(\mathrm{n}=83)\end{array}$ & $\begin{array}{c}100.0 \\
(\mathrm{n}=631)\end{array}$ \\
\hline $\begin{array}{c}\text { In your lifetime? } \\
\text { (n=296) }\end{array}$ & $\begin{array}{c}11.3 \\
(\mathrm{n}=74)\end{array}$ & $\begin{array}{c}6.6 \\
(\mathrm{n}=43)\end{array}$ & $\begin{array}{c}3.8 \\
(\mathrm{n}=25)\end{array}$ & $\begin{array}{c}6.0 \\
(\mathrm{n}=39)\end{array}$ & $\begin{array}{c}6.6 \\
(\mathrm{n}=43)\end{array}$ & $\begin{array}{c}20.4 \\
(\mathrm{n}=133)\end{array}$ & $\begin{array}{c}100.0 \\
(\mathrm{n}=653)\end{array}$ \\
\hline
\end{tabular}

"use it less than I do now,"

"use it about as often as I do now," and

"use it more often than I do now."

\section{RESULTS}

Table 1 shows the prevalence of marijuana use for our sample. Approximately 45 percent of respondents self-reported using on zero occasions in their lifetime, while nearly 55 percent reported using on one or more occasions during their lifetime. Additionally, 59 percent $(n=372)$ of our respondents reported using marijuana on zero occasions in the last 12 months. For the purpose of this study, these 372 respondents were identified as abstainers, along with the 296 that reported zero use in their lifetime. When looking at the users of marijuana, approximately 41 percent $(n=259)$ of respondents admitted to using marijuana anywhere between one and 40 or more occasions in the last year. Approximately 74 percent of respondents self-reported not using marijuana in the last 30 days and 25.9 percent self-reported using marijuana on one or more occasions in the past month.

Table 2 displays the results for the most commonly reported reasons for non-use among abstainers. The top three reasons for non-use include "don't feel like getting high" (44.4 percent), "concerned about getting arrested" (42.2 percent), and "my parents would disapprove" (33.6 percent). Concerned about getting arrested is highlighted because as deterrence theory would suggest these individuals might be more likely to use marijuana once criminal sanctions are removed. The least commonly reported reasons for non-use are "not available" and "I might have a bad trip."

Examining the most commonly reported reasons for individual marijuana use, Table 3 shows the top three reasons are "to have a good time with friends" (70.9 percent), "to relax or relieve tension" (67.8 percent), and "to feel good or get high" (61.6 percent). The least commonly reported reasons include "to increase the effect of some other drug(s)" (5.0 percent), "to decrease the effect of some other drug(s)" (4.7 percent), and because "I am "hooked" - I have to have it” (1.6 percent).

When looking at the four contexts for possible use, we report the means on a scale of one to ten with higher scores indicating higher perceived likelihood of

Table 2: Reported Reasons for Non-use Among Abstainers in Percentages $(n=369)$

\begin{tabular}{|c|c|c|}
\hline & $\%$ & $\mathbf{n}$ \\
\hline Don't feel like getting high & 44.4 & 292 \\
\hline Concerned about getting arrested & 42.2 & 278 \\
\hline My parents would disapprove & 33.6 & 221 \\
\hline $\begin{array}{l}\text { Concerned about possible } \\
\text { psychological damage }\end{array}$ & 28.6 & 188 \\
\hline $\begin{array}{c}\text { Concerned about possible physical } \\
\text { damage }\end{array}$ & 28.4 & 187 \\
\hline $\begin{array}{l}\text { Concerned about loss of energy and } \\
\text { ambition }\end{array}$ & 26.6 & 175 \\
\hline $\begin{array}{l}\text { I don't like being with the people who } \\
\text { use it }\end{array}$ & 22.5 & 148 \\
\hline Too expensive & 21.0 & 144 \\
\hline Not enjoyable, I didn't like it & 20.7 & 136 \\
\hline It's against my beliefs & 20.2 & 133 \\
\hline $\begin{array}{l}\text { Concerned about possible loss of } \\
\text { control of myself }\end{array}$ & 19.8 & 130 \\
\hline It might lead to stronger drugs & 19.6 & 129 \\
\hline $\begin{array}{l}\text { My husband/wife (or } \\
\text { boyfriend/girlfriend) would disapprove }\end{array}$ & 17.0 & 112 \\
\hline $\begin{array}{c}\text { Concerned about becoming addicted } \\
\text { to marijuana }\end{array}$ & 15.3 & 101 \\
\hline My friends don't use it & 14.0 & 92 \\
\hline Not available & 9.0 & 59 \\
\hline I might have a bad trip & 8.1 & 53 \\
\hline
\end{tabular}


Table 3: Reported Reasons for Use in Percentages $(n=258)$

\begin{tabular}{|c|c|c|}
\hline & $\%$ & $\mathbf{n}$ \\
\hline To have a good time with my friends & 70.9 & 183 \\
\hline To relax or relieve tension & 67.8 & 175 \\
\hline To feel good or get high & 61.6 & 159 \\
\hline To experiment & 46.1 & 119 \\
\hline $\begin{array}{l}\text { To seek deeper insights and } \\
\text { understanding }\end{array}$ & 36.8 & 95 \\
\hline Because of boredom, nothing else to do & 27.5 & 71 \\
\hline $\begin{array}{l}\text { To get away from my problems or } \\
\text { troubles }\end{array}$ & 23.6 & 61 \\
\hline Because of anger or frustration & 18.2 & 47 \\
\hline To get through the day & 11.6 & 30 \\
\hline To fit in with a group I like & 8.9 & 23 \\
\hline $\begin{array}{l}\text { To increase the effects of some other } \\
\text { drug(s) }\end{array}$ & 5.0 & 13 \\
\hline $\begin{array}{c}\text { To decrease (offset) the effects of some } \\
\text { other drug(s) }\end{array}$ & 4.7 & 12 \\
\hline $\begin{array}{l}\text { Because I am "hooked" - I have to have } \\
\text { it }\end{array}$ & 1.6 & 4 \\
\hline
\end{tabular}

use. Table 4 shows the means scores for each of the four contexts. The first thing to note is that as all four means are low, ranging from 1.4 to a high of 1.90 , suggesting that among abstainers (operationalized as those who have not used in the past 12 months), the perceived likelihood of using is very small regardless of the hypothetical situation. The two contexts with the lowest likelihood of use was if it was illegal, but your best friend was using it at 1.40 and if they were visiting Colorado or Washington states where recreational use is legal at 1.71. The two highest contexts include using if marijuana was legalized in this state with a mean of 1.84 and if visiting Amsterdam, Netherlands where marijuana use is decriminalized at 1.90 . It should be noted that there were no statistically significant differences between the mean likelihood of use across the four contexts.

Table 4: Mean of Four Contexts Measuring the Degree of Criminal Justice Sanctions

\begin{tabular}{|c|c|}
\hline & Mean \\
\hline \hline $\begin{array}{c}\text { If visiting Amsterdam, Netherlands where the } \\
\text { official drug policy is one of tolerance and } \\
\text { marijuana use is decriminalized }\end{array}$ & 1.90 \\
\hline If it was legalized in this state & 1.84 \\
\hline $\begin{array}{c}\text { If visiting Colorado and Washington states where } \\
\text { marijuana is legalized }\end{array}$ & 1.71 \\
\hline If it was illegal, but your best friend was using it & 1.40 \\
\hline
\end{tabular}

In regards to the primary research question, Table $\mathbf{5}$ shows that approximately 62 percent of abstainers report they definitely will not use marijuana even if it were legal in the state they reside in five years from now, while a modest 8.4 percent of abstainers reported they "definitely" (1.1 percent) or "probably" (7.3 percent) would use.

Table 5: Likelihood of Use If Marijuana were Legal Five Years from Now $(n=365)$

\begin{tabular}{|c|c|c|}
\hline & \% & $\mathbf{n}$ \\
\hline \hline I definitely will not & 61.8 & 228 \\
\hline I probably will not & 28.7 & 106 \\
\hline I probably will & 7.3 & 27 \\
\hline I definitely will & 1.1 & 4 \\
\hline
\end{tabular}

Table 6 reveals the likelihood to use marijuana if it were legal and legally available. Here, approximately 77 percent of abstainers report that they would not use, even if marijuana were legal and legally available. However, 17 percent of abstainers reported they would at least try marijuana with the removal of criminal sanctions.

Table 6: Likelihood to Use if Marijuana were Legal and Legally Available $(n=368)$

\begin{tabular}{|c|c|c|}
\hline & $\%$ & $\mathbf{n}$ \\
\hline \hline Not use, even if it were legal and available & 77.2 & 285 \\
\hline Try it & 16.8 & 62 \\
\hline Use it less than I do now & 0.3 & 1 \\
\hline Use it about as often as I do now & 3.3 & 12 \\
\hline Use it more often than I do now & 2.2 & 8 \\
\hline
\end{tabular}

\section{DISCUSSION AND CONCLUSIONS}

Respondents in our study report higher rates of marijuana use than what has been found in previous, nationwide studies. For example, when looking at past year marijuana use, CORE (2012) found that in 2010 approximately 31 percent of college students had used marijuana in the past year while a 2009 MTF study reported similarly that approximately 33 percent of college students admitted past year use (Johnston et al. 2010:8). We, however, found that approximately 41 percent of undergraduate students reported using marijuana in the past year while 55 percent had used in their lifetime and 25.9 percent had used in the last 30 days. The 2009 MTF study reported slightly lower rates for lifetime (47.5) and past month use (18.5) (Johnston, 
et al. 2010:37). Since the comparison studies were conducted four to five years before the current research, it is possible that higher rates found are due to changes in social norms regarding use (Keyes et al. 2011:2). That is, maybe with the increasingly liberalization of marijuana policies and attitudes around the country, the negative social stigma associated with marijuana use is simply not as great as it was previously. However, it is also possible that students in the current study differ on the whole from the general population of college students. Unfortunately, we are unable to discern the plausibility of either explanation.

When looking at reasons for non-use, "don't feel like getting high" was the primary reason stated for not using marijuana with approximately 61 percent of respondents choosing this as at least one explanation for nonuse. Terry-McElrath et al. (2008) found consistent results, noting that approximately 62 percent of their respondents did not use marijuana because they did not feel like getting high, which was only exceeded by concern for the possible psychological or physical damage. In the current research, concern about getting arrested was the second most commonly reported reason with 50 percent of respondents choosing this as at least one reason for not using, which is slightly higher than previous studies. TerryMcElrath et al. (2008), for example, found that concern about getting arrested was a reason for not using for only 45 percent of respondents. However, it is important to note that over time concern about getting arrested has seemingly increased since the 1980s when only about 40 percent of individuals reported it as an explanation for nonuse. This increase in fear of criminal sanctions is no doubt at least in part an outgrowth of America's ongoing and well-publicized "war on drugs," which has drastically increased penalties for drug-related crimes. These increases and the fact that fully half of the respondents in the current study report fear of arrest as a primary motive of not smoking marijuana, provide support for the notion that criminal sanctions may serve as a deterrent at least among abstainers.

While the possibility of legal consequences serves as a reason for nonuse for some, it does not appear that the removal of this prospect would increase use among current abstainers. As noted above, the likelihood for use was negligible for each of the four contexts presented to the participants. In fact all of the means on a scale of one to ten, with higher means indicating greater likelihood of use, were less than two. This lends some support to the notion that marijuana use will not significantly increase with the removal of criminal sanctions. The highest likelihood of use with a mean score of 1.91 was if visiting Amsterdam, where marijuana use is decriminalized. This small but higher score in relation to the other contexts might be due to the fact that the question asks about a city overseas. It is clear from our study as well as previous studies that not only does formal social control exert some influence over whether one uses marijuana but so does informal controls such as family and peers. Regardless of its legal status, there will remain in some circles a negative social stigma attached to smoking marijuana much like attitudes toward cigarettes and alcohol consumption. It is then possible that the perceived negative social stigma may be lessened by the increased anonymity that comes with being in a different part of the world. Thus, it may that the decriminalization (or legal) status and increased anonymity may combine to increase the likelihood of use in this situation relative to the others. The likelihood of use if marijuana remained illegal, but their best friend was smoking had the lowest mean of all four contexts. This may be expected as all criminal sanctions remain intact, which may deter use. However, as other studies have reported, marijuana use should be higher because of peer influence. Interestingly, this study does not support that conclusion.

When looking at the affect of the removal of all criminal sanctions on whether abstainers would try marijuana or would use marijuana five years from now, we again find that rates of anticipated use are generally low. For example, when asked if they would use marijuana if it were legal and legally available, 17 percent of abstainers did report they would "try" it, but 77.1 percent indicated that they would not use at all. When asked about use in five years if it was legal only 8.4 percent reported they would "definitely" or "probably" use marijuana but 62.5 percent dismissed the thought entirely. Thus, an interesting difference seems to emerge between those who reported they would try it if it were legal and legally available (17 percent) and those who would definitely or probably use it in five years if it was legal (8.4 percent). This difference may be explained by how one perceives "try" versus "use." It may be that the former is associated with experimentation, where the latter is interpreted as "continued use" as one might "use" cigarettes or alcohol. Another interesting result is the difference between those who definitely would not use five years from now (62.5 percent) and those who would not use even if it were legal and available (77.1 percent). An explanation for this difference may be attributed to the 
time dimension. Individuals might report being more likely to use in five years from now than they are today even if it were legal because they may be concerned about how present drug use might affect future opportunities, particularly in regards to getting jobs in a culture where workplace drug testing is an increasingly more common condition of employment. Additionally, as we surveyed college students, individuals may not use marijuana for fear of academic problems. Kilmer, Hunt, Lee, and Neighbors (2007), for example, found that approximately 71 percent of college students reported not smoking pot because they were concerned that using or trying marijuana may interfere with their ability to get good grades. Thus, even if attitudes towards marijuana use becomes more accepting and even legal, an individual may still not use because of the affect it may have on their academic performance. This was also demonstrated by MTF studies, which have indicated that seniors who have good grades in school and who were never truant were less likely to use marijuana than the average senior (Bachman, Johnston, and O'Malley, 1998:887).

The primary focus of this research was to examine anticipated levels of marijuana use among abstainers if criminal sanctions were removed or at least partially removed. As deterrence theory would suggest removing the possibility of punishment should translate into an increase in the previously prohibited behavior. Opponents of legalization also express this fear. Reinarman, Cohen, and Kaai (2004:836) reported that one of the largest perceived negative aspect of marijuana legalization is that once the threat of punishment is gone, the prevalence, frequency, and quantity of cannabis use will increase (Reinarman et al. 2004:836). Results from this study do not necessarily support this assertion. While almost half of the respondents reported not using due to fear of arrest and 17 percent of abstainers did report that they would "try" marijuana if it were legal and legally available, only about eight percent reported they would definitely or probably use marijuana if it were legal five years from now. Additionally, the large majority of respondents reported there was a zero percent likelihood they would use regardless of its legal status. Finally, when examining likelihood of use over four different contexts, abstainers indicated that there was almost no chance that they would use in any of the situations presented. These findings suggests that those who do not currently use marijuana choose not to for reasons other than fear of criminal sanctions So, while there may be other reasons for the criminalization of marijuana use, it does not appear that deterrence is an overarching one (Boyum, Caulkins, and Kleiman 2011:375).
Of course, we must be careful of reading too much in to the results of this single study. As is the case with all studies, we acknowledge that there are a number of limitations that should be noted and addressed in future research. First and most obvious is that the results cannot be generalized beyond the scope of this study. Future research should examine such questions using more nationally representative samples rather than just college students in a single locale. Respondents were also asked about hypothetical situations. Abstainers were asked to discuss the possibility of future use under a variety of contexts in which they may or may not someday face. It is certainly possible that actual actions will be different than reported actions if and when marijuana use is legalized. It is difficult to accurately predict how one will act in the future as our experiences, interests and circumstance change over time and influence how we behave. Finally, respondents were not asked to assess the likelihood of punishment. One of the important components of deterrence theory is that punishment can only be an effective deterrent if it is certain. Unfortunately, this study does not assess the degree to which respondents believe that they would be caught and punished. It is possible that many did not indicate fear of arrest as a reason for not using simply because they did not perceive the probability of detection and/or punishment as very high.

In light of recent policy shifts and changing attitudes toward marijuana use, this study provides an important contribution to previous literature on marijuana use. Specifically, we are one of the first studies in this current milieu to attempt to assess the possible impact that legalization may have on future use. While, this study suggests that the removal of criminal sanctions will at best have a modest effect on future use, subsequent research is needed to support this assertion.

\section{REFERENCES}

Abiodun, P. Bamigboye and A.M. Afolayan. 2007. "Pattern of Marijuana Use among Male University Students: A Case Study." Journal of Medical Science 7(6):1068-1072. http://dx.doi.org/10.3923/jms.2007.1068.1072

Andenaes, Johannes. 1966. "The General Preventive Effects of Punishment." University of Pennsylvania Law Review, 114(7):949-983. http://dx.doi.org/10.2307/3310845

Bachman, Jerald G., Lloyd D. Johnston, and Patrick M. O'Malley. 1998. Explaining Recent Increases in Student' Marijuana Use: Impacts of Perceived Risks and Disapproval, 1976 through 1996. American Journal of Public Health 88(6):887892. http://dx.doi.org/10.2105/AJPH.88.6.887

Beaudoin, Christopher E. and Traci Hong. 2012. "Media Use and Perceived Risk as Predictors of Marijuana Use." American Journal of Health Behavior 36(1): 134-143. http://dx.doi.org/10.5993/AJHB.36.1.14 
Boyum, David A., Jonathan P. Caulkins, and Mark A. R. Kleiman 2011. Drugs, Crime, and Public Policy. Crime and Public Policy. Oxford University Press: New York, New York.

Burkett, Steven R. and Eric L. Jensen. 1975. "Conventional Ties, Peer Influence, and the Fear of Apprehension: a Study of Adolescent Marijuana Use." The Sociological Quarterly, 16 (4): 522-533.

http://dx.doi.org/10.1111/j.1533-8525.1975.tb00966.x

Chiricos, Theodore G. And Gordon P. Waldo. 1970. "Punishment and Crime: An Examination of Some Empirical Evidence." Social Problems, 18:200-217. http://dx.doi.org/10.2307/799582

Cole, James M. 2013. Memorandum for All United States Attorneys: Guidance Regarding Marijuana Enforcement. Office of the Deputy Attorney General.

Dierker, Lisa, Marilyn Stolar, Elizabeth Lloyd-Richardson, Stephen Tiffany, Brian Flay, Linda Collins, Mimi Nichter, Mark Nichter, Steffani Bailey, Richard Clayton, and the Tobacco Etiology Research Network (TERN). 2008. "Tobacco, Alcohol, and Marijuana Use Among First-Year U.S. College Students: A Time Series Analysis." Substance Use \& Misuse, 43(5):680699.

\section{http://dx.doi.org/10.1080/10826080701202684}

Erickson, Patricia G., Mark Van Der Maas, and Andrew D. Hathaway. 2013. "Revisiting Deterrence: Legal Knowledge, Use Context, and Arrest Perception for Cannabis." Czech Sociological Review, 49(3):427-448.

Ferner, Matt. 2012. “Gov. John Hickenlooper Opposed Legal Weed: 'Colorado is Known for Many Great Things. Marijuana Should Not be One of Them." The Huffington Post, September 12. Retrieved from http://www.huffingtonpost.com/2012/09/12/ gov-john-hickenlooper-opp_n_1879248.html

Gibbs, Jack P. 1968. 'Crime, Punishment and Deterrence.' Southwestern Social Science Quarterly, 48:515-530.

Johnson, Gene. 2013. "Marijuana Legalization: Opponents Regroup Following Washington, Colorado Votes." The Huffington Post, January, 9 ${ }^{\text {th }}$. Retrieved from http://www.huffingtonpost. com/2013/01/09/marijuana-legalization_n_2441903.html?

Johnston, Lloyd D., Patrick M. O'Malley, Jerald G. Bachman, and John E. Schulenberg. 2013. "Monitoring the Future: National Survey Results on Drug Use, 1975-2012."

Johnston, Lloyd D., Patrick M. O'Malley, Jerald G. Bachman, and John E. Schulenberg. 2010. "Monitoring the Future: National Survey Results on Drug Use, 1975-2009:1-305."

Keyes, Katherine M., John E. Schulenberg, Patrick M. O’Malley, Lloyd D. Johnston, Jeralg G. Bachman, Guohua Li, and Deborah Hasin. 2011. "The Social Norms Of Birth Cohorts and Adolescent Marijuana Use in The United States, 19762007." Addiction 106(10):1790-1800. http://dx.doi.org/10.1111/j.1360-0443.2011.03485.x

Kilmer, Jason R., Scott B. Hunt, Christine M. Lee, and Clayton Neighbors. 2007. "Marijuana Use, Risk Perception, and Consequences: Is Perceived Risk Congruent with Reality?" Addictive Behaviors, 32:3026-3033. http://dx.doi.org/10.1016/j.addbeh.2007.07.009

Kohn, Paul M. and G.W. Mercer. 1971. "Drug Use, Drug-Use Attitudes, and the Authoritatianism-Rebellion Dimension." Journal of Health and Social Behavior, 12: 125-131. http://dx.doi.org/10.2307/2948519
LaBrie, Joseph W., Justin F. Hummer, and Andrew Lac. 2011. "Comparing Injunctive Marijuana Use Norms of Salient Reference Groups Among College Student Marijuana Users And Nonusers." Addictive Behaviors, 36: 717-720. http://dx.doi.org/10.1016\%2Fj.addbeh.2011.02.004

MacCoun, Robert J. 1993. "Drugs and the Law: A Psychological Analysis of Drug Prohibition." Psychological Bulletin, 113(3):497-512. http://dx.doi.org/10.1037//0033-2909.113.3.497

Reinarman, Craig, Peter D.A. Cohen, and Hendrien L. Kaal. 2004. "The Limited Relevance of Drug Policy: Cannabis in Amsterdam and in San Francisco." American Journal of Public Health 94(5):836-842. http://dx.doi.org/10.2105/AJPH.94.5.836

SIUC/Core Institute. 2012. "Core Alcohol and Drug Survey Long Form." Retrieved from http://www.core.siuc.edu/ August 17, 2015.

Single, Eric W. 1989. "The Impact of Marijuana Decriminalization: An Update." Journal of Public Health Policy, 10(4):456-466. http://dx.doi.org/10.2307/3342518

Substance Abuse and Mental Health Services Administration. 2012. Results from the 2011 National Survey on Drug Use and Health: Summary of National Findings. NSDUH Series $\mathrm{H}-44$, HHS Publication No. (SMA) 12-4713. Rockville, MD:

Substance Abuse and Mental Health Services Administration. Retrieved from http://store.samhsa.gov/home August 1st, 2015.

Swift, Art. 2013. For First Time, Americans Favor Legalizing Marijuana. Gallup Politics. Retrieved from http://www.gallup. com/poll/165539/first-time-americans-favor-legalizingmarijuana.aspx

Terry-McElrath, Yvonne M., Patrick O’Malley, and Lloyd D. Johnston. 2008. "Saying No to Marijuana: Why American Youth Report Quitting or Abstaining." Journal of Studies on Alcohol and Drugs, 69(6): 796-805. http://dx.doi.org/10.15288/jsad.2008.69.796

Tittle, Charles R. 1969. "Crime Rates and Legal Sanctions." Social Problems, 16:409-423. http://dx.doi.org/10.2307/799950

Wadley, Jared. 2012. “'Monitoring the Future' Receives \$35 Million to Continue for Another Five Years." University of Michigan: Institute for Social Research. Retrieved from http://home.isr. umich.edu/releases/monitoring-the-future-receives-35million-to-continue-for-another-five-years/

Waldo, Gordon P. And Theodore G. Chiricos. 1972. "Perceived Penal Sanction and Self-Reported Criminality: A Neglected Approach to Deterrence Research." Social Problems, 19(4):522-540. http://dx.doi.org/10.2307/799929

Walker, Samuel. 1994. "Sense and Nonsense about Crime and Drugs: A Policy Guide." $3^{\text {rd }}$ edition. Wadsworth Publishing Company: Belmont, California.

Wing, Nick. 2013. "Jimmy Carter Comes Out Against Marijuana Legalization, Wants to 'Discourage' Use Of Pot." The Huffington Post. Retrieved from http://www.huffingtonpost. com/2013/05/17/jimmy-carter-marijuanalegalization_n_3293861.html

(C) 2015 Arazan et al.; Licensee Lifescience Global.

This is an open access article licensed under the terms of the Creative Commons Attribution Non-Commercial License (http://creativecommons.org/licenses/by-nc/3.0/) which permits unrestricted, non-commercial use, distribution and reproduction in any medium, provided the work is properly cited. 